\title{
Properties of Fibers Prepared from Oil Palm Empty Fruit Bunch for Use as Corru- gating Medium and Fiberboard
}

\author{
Harsono $^{* 2}$, Lilik Tri Mulyantara ${ }^{* 2}$, \\ Andri Taufick Rizaluddin ${ }^{* 3}$, \\ Akiko Nakagawa-izumi and Hiroshi $\mathrm{Ohi}^{* 4}$ \\ Graduate School of Life and Environmental Sciences, University of Tsukuba*1

\section{Keiichi Nakamata} \\ Technical and Development Division, Hokuetsu Kishu Paper Co., Ltd.
}

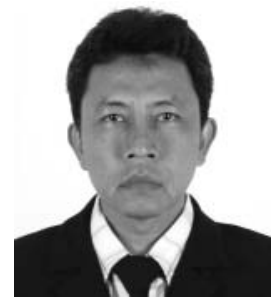

Harsono

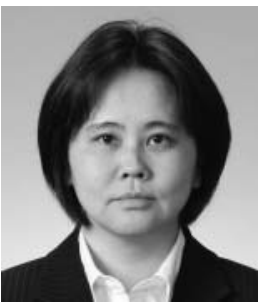

Akiko Nakagawa-izumi

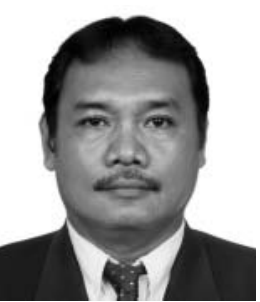

Lilik Tri Mulyantara

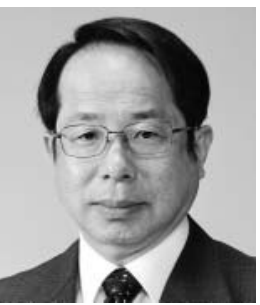

Hiroshi Ohi

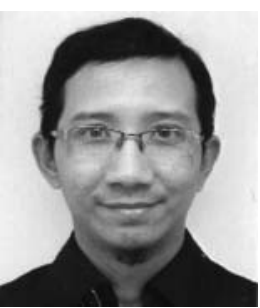

Andri Taufick Rizaluddin

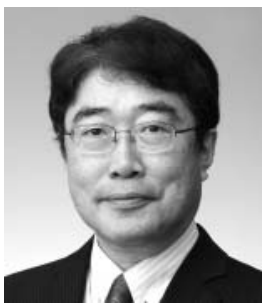

Keiichi Nakamata

\begin{abstract}
This research was aimed at improving the utilization of waste generated by the palm oil industry by identifying the conditions needed to make fibers suitable for products such as paperboard and fiberboard from the empty fruit bunch (EFB) of oil palm (Elaeis guineensis). For this, the chemical pretreatment conditions needed to mechanically produce a pulp for paperboard were studied, as well as the effects of varying these conditions on the fiber properties. The optimum conditions to achieve the highest paper strength were found to be a $\mathrm{NaOH}$ dosage of $2 \%$, pretreatment time of $2 \mathrm{~h}$ at $121^{\circ} \mathrm{C}$ and refiner disk-clearance of $0.10 \mathrm{~mm}$. This EFB pulp exhibited similar tensile and tear indices to a pulp prepared from an old corrugated fiberboard box, and on the basis of this, it was considered acceptable for use in corrugating medium. Subsequent fabrication of fiberboard and clarification of its resistance to fungal attack found that the mechanical properties of EFB fiberboard made from unre-
\end{abstract}

\footnotetext{
${ }^{* 1} 1-1-1$ Tennodai, Tsukuba, Ibaraki, 305-8572 Japan

${ }^{* 2} \mathrm{E}-$ mail : h2r50@yahoo.co.id, Center of Agricultural Engineering Research and Development, Ministry of Agriculture in Indonesia

${ }^{* 3} \mathrm{E}-$ mail : andritr3@gmail.com, Center for Pulp and Paper, Ministry of Industry in Indonesia

${ }^{* 4} \mathrm{E}$-mail : oi.hiroshi.gm@u.tsukuba.ac.jp
}

Received : August 26, 2015 Accepted : September 24, 2015

J-STAGE Advance Published : October 16, 2015 
fined fibers are lower than Japanese Industrial Standards ; however, its resistance to brown-rot and white-rot fungus is better than that of board made from sugi (Cryptomeria japonica).

Keywords : oil palm empty fruit bunch, mechanical pulp, paperboard, fiber classification, tensile index

\section{Introduction}

\subsection{Palm oil industry in Indonesia}

Indonesia is a tropical country with a high rainfall and the largest producer of palm oil in the world. In 2013, around 26 million tons of crude palm oil (CPO) was produced from 11 million ha of plantation areas. As one of the main products of palm oil fruit, this oil can be used by the food industry for the production of cooking oil, margarine, and ice cream, or the non-food industries for producing candles, soap, shampoo, detergent, lubricant, cosmetics, and pharmaceutical products.

Plantations of oil palm (Elaeis guineensis) in Indonesia have been developed mostly on the islands of Sumatera, Kalimantan, and Sulawesi, resulting in an increased income for these communities and overall value of Indonesian exports. Palm oil also represents a strategic industry in other tropical countries such as Malaysia and Thailand, in that it is expected to support national economic growth in the future. Despite these positive impacts, there are environmental concerns related to the processes used both in the palm fields and factories to separate $\mathrm{CPO}$ and palm kernel oil (PKO), as these generate pollution in the form of liquid, solid and gaseous waste products. As shown in Photo. 1, a fruit bunch of about $50-60 \mathrm{~cm}$ in length is harvested from palm oil trees (usually about $3-15 \mathrm{~m}$ height), and is then separated into $3-5 \mathrm{~cm}-$ long palm fruits and an empty fruit bunch (EFB). This process invariably leaves residues such as the kernel shell, fruit fibers, fronds, palm kernel cake and EFB wastes, most of which are unutilized.

\subsection{Utilization of empty fruit bunch (EFB)}

Although EFB is the main by-product of palm fruit and oil industries, it is generally left rotting at the plantation site without any further processing (Photo. 1). On average, EFB represents around $22-24 \%$ of the total weight of fresh fruit bunches (palm fruits : 63\% ; moisture : 13\%) processed in palm oil mills, and so clearly action must be taken to reduce the negative impact of this waste. One possible solution is to utilize this waste for other purposes, thereby increasing the positive impacts of the palm fruit and oil industries ${ }^{1)}$. EFB has considerable potential to be used in organic fertilizers or animal fodder, and for use as a raw material for brick and mat-making, or as a growth media for fungi and plants, and as a lignocellulosic raw material for paper making.

Compared to other woody materials, non-wood raw ma- terials tend to have a similar cellulose content, but are lower in lignin and higher in hemicelluloses and silica ${ }^{2}$. This gives non-wood materials like EFB some advantages when used in pulp and paper processes, which has led to a number of researchers studying this possibility. For instance, Tanaka et al. ${ }^{3)}$ and Jimenez et al. ${ }^{4)}$ have suggested that paper sheets can be produced from EFB, while Singh et $a l .^{5)}$ have discussed the prospect of using EFB for the manufacture of pulp and paper. The production of pulp for paper making from non-wood fibrous materials has grown significantly with the increasing demand for paper and paper products, especially when wood supplies have proven insufficient. Some research into the use of EFB as a dissolving pulp has also been undertaken ${ }^{6-8}$, but the optimal conditions required to reach an acceptable standard of quality have not been determined. Thus, further research is needed into the optimal conditions required to produce dissolving pulp and paper from EFB through chemical and mechanical pulping.

It is well-known that EFB morphologically consists of various kinds of plant cells ${ }^{9}$, but sourcing it as a byproduct introduces some undesired characteristics from a utilization point of view. For example, as EFB residue is quite bulky and contains a large amount of moisture, it is difficult to dry and often retains a small amount of oil ${ }^{10)}$. This makes it necessary to reduce the size of the material to facilitate drying and transport. As a lignocellulosic material, EFB contains around 18-23\% lignin, 35\% $\alpha$-cellulose, and $25 \%$ hemicellulose ${ }^{11)}$. This has prompted several studies into the use of EFB waste as a wood replacement material in the creation of particleboard ${ }^{12)}$, $\operatorname{composites}^{13)}$ or briquettes $^{14)}$. In addition, lignin and carbohydrates isolated from EFB have the potential to provide the resources for new biomaterials and bioethanol production.

\subsection{Mechanical and chemi-thermomechanical pulp- ing}

Mechanical pulping is typically used for softwood and offers the advantage of a great yield of around $85-95 \%$ of the dried weight of the input material. However, its disadvantages are that it requires a great deal energy, and the strength of mechanical pulps is generally weaker than that of chemical pulps. An example of mechanical pulping is refiner mechanical pulping (RMP), in which wood chips are shredded into fibers between large rotating disks to increase the contact area of the cell walls of a fiber by increasing its flexibility. The process also increases the total 


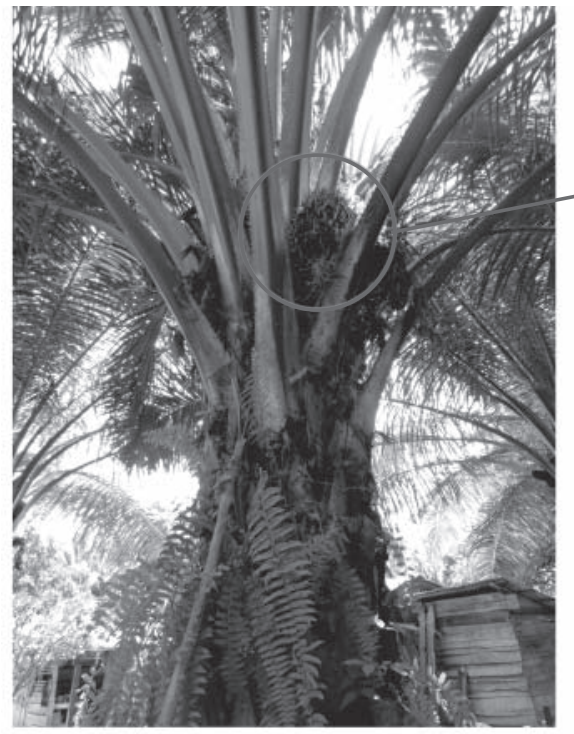

Palm Oil Tree (Productive stem height: $3-15 \mathrm{~m}$ )

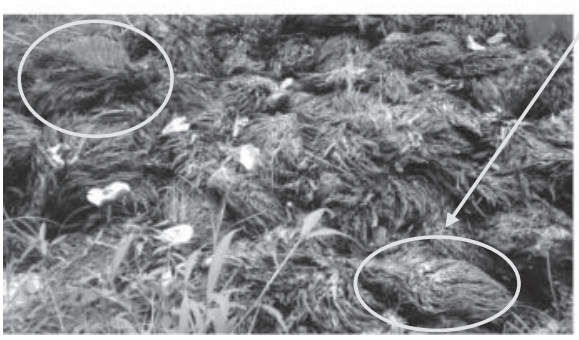

EFBs at the plantation site (Moisture content 50-60\%)

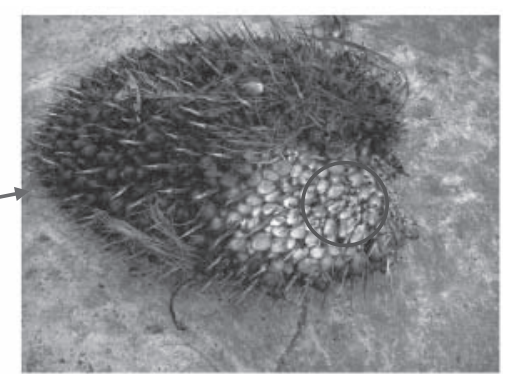

Fruit Bunch (50-60 cm in length)

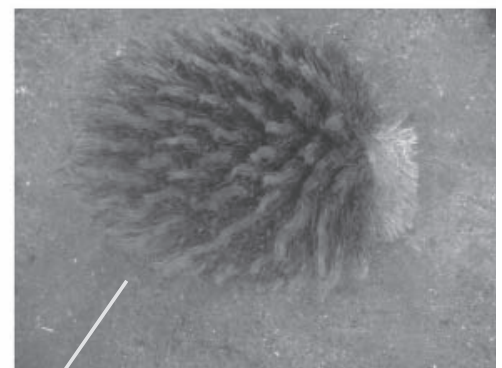

Empty Fruit Bunch (EFB)

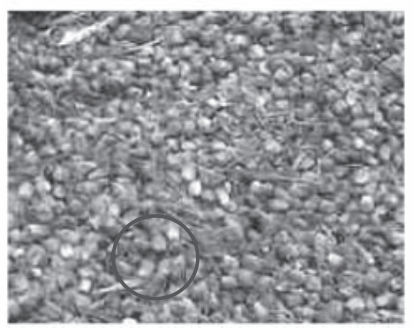

Palm Fruits $(3-5 \mathrm{~cm})$

Photo. 1 Separation of empty fruit bunch (EFB) from oil palm tree

surface area available for bonding through fibrillation of the external surface. The weaker strength of the pulp sheets can be attributed to the mechanical damage caused by separating the fibers, with paper made from mechanical pulp tending to become brittle with age because of its lignin and having a shorter useful life than paper made from chemical pulp.

The basic RMP process has evolved to incorporate thermal and/or chemical pre-softening of the wood chips, which reduces energy usage and modifies the properties of the resultant pulp. These are typically referred to as thermo-mechanical pulping (TMP) and chemi-thermomechanical pulping (CTMP), respectively. The quality of both the pulp and paper is influenced by both the material quality and the refining conditions used ${ }^{15,16}$. In the TMP process the wood chips are steamed for several minutes under pressurized conditions, which soften the lignin, and are then refined through one or two stages. In contrast, the CTMP of softwood chips involves treating with a mild sulfite solution to modify the lignin and slightly remove a part of wood components prior to refining, but this also has the effect of reducing the pulp yield $85-90 \%$.
Some hardwoods require chemical pre-treatment to produce a suitable mechanical pulp, which has led to the development of alkaline peroxide mechanical pulping (BCTMP or APMP). This offers several advantages in terms of providing good pulp qualities and energy savings compared to conventional CTMP, making it a good pulping method for low-density hardwoods such as for aspen and eucalyptus ${ }^{17)}$. This method is used along with TMP and CTMP to treat the raw materials used to create papers such as newsprint and printing paper. This study though looks at the possibility of using EFB as a raw material for paperboards and fiberboards.

\subsection{Objectives of this study}

The goal of this study is to improve the utilization of waste from the palm oil industry by identifying products that can be manufactured from EFB. To this end, the optimal treatment conditions needed to produce mechanical pulp for paperboard were first identified, and were then applied to creating medium density fiberboard (MDF) from EFB. As the complex structure of organic materials in these EFB fiberboards can potentially provide a food source for mold, and fungi, and termites, the second objec- 
tive was to evaluate the degradation resistance of EFB fiberboards. The final objective was to utilize EFB waste as a raw material for manufacturing $\mathrm{MDF}$.

\section{Experimental}

\subsection{Raw materials for paperboard and fiberboard}

Two kinds of EFB material were obtained from the palm oil mills of PT. Perkebunan Nusantara VIII in Bogor, West Java, Indonesia. Unrefined EFB fibers were obtained from these materials through several stages of processing. The EFB byproducts were shredded into long fiber fragments $(10-15 \mathrm{~cm})$, sun-dried until reaching $8-10 \%$ moisture, and then further cut into $0.2-1.0 \mathrm{~cm}$ or $0.5-4.0 \mathrm{~cm}$ lengths by a laboratory disk mill.

\subsection{Production of chemically pretreated-mechanical pulp}

The EFB fibers cut to a length $0.5-4.0 \mathrm{~cm}$ were used for making a mechanical pulp by means of a thermo-mechanical pulp (TMP) refiner (Kumagai Riki Kogyo Co., LTD., Nerima, Tokyo) with a disk clearance set to 0.10 , 0.15 or $0.20 \mathrm{~mm}$. The chemical pretreatment conditions used were as follows : liquor to EFB fiber ratio : $7 \mathrm{~L} / \mathrm{kg}$; $\mathrm{NaOH}$ addition level $: 0,1$, or $2 \%$ based on the ovendried weight of EFB fibers ; pretreatment temperature and time $: 121^{\circ} \mathrm{C}$ for 1,2 , or $3 \mathrm{~h}$. After pretreatment, the yield loss and $\mathrm{pH}$ of the liquor were determined. Refining of the pretreated EFB fibers was carried out under atmospheric conditions as no way could be found of feeding sufficient fibrous material into the disk-process otherwise.

\subsection{Evaluation of chemically pretreated mechanical} pulp

Classification of the refined fibers (i. e., the fiber length distribution) was conducted according to Japanese Industrial Standards (JIS) P 8207 (pulp test method for classification with screen) using 710, 355, 180 and $75 \mu$ m opening screens (24, 42, 80 and 200 mesh, respectively). After chemi-mechanical pulping, the refined pulp was further refined by a PFI mill at some beating revolution, and the physical properties of handsheets were determined along with the tensile and tear indices in accordance with ISO 5270, ISO 1924, and ISO 1974, respectively. The fiber length and fiber width of some pulps were also determined using a Lorentzen-Wettre fiber tester CODE 912.

\section{4 Preparation of EFB fiberboard}

Fiberboard was made from unrefined EFB fibers (0.2$1.0 \mathrm{~cm}$ in length) by first blending dried EFB fibers with $12 \%$ melamine urea formaldehyde (MUF) resin and $1 \%$ wax (based on EFB oven-dried weight). This mixture was manually distributed in a wood mold to form mats, which were then cold-pressed at $3 \mathrm{MPa}$ for 30 seconds, followed by hot-pressing $\left(180^{\circ} \mathrm{C}\right)$ at $5 \mathrm{MPa}$ for 60 seconds. For comparison, MDF was also made from refined fibers of mixed light hardwoods (MLH) provided by a MDF mill. The dimensions of the EFB fiberboards and hardwood MDF was $300 \times 300 \times 12 \mathrm{~mm}(9 \mathrm{~mm}$ after polishing), with a target density of $700 \mathrm{~kg} / \mathrm{m}^{3}$. All samples were conditioned at $20^{\circ} \mathrm{C}$ and $65 \%$ relative humidity for a week. The above experiment was conducted by Dr. Hideaki Takahashi of Hokushin Co., Ltd., Kishiwada, Osaka.

\subsection{Preparation of EFB pellet}

Trials of pelletizing EFB fibers $(0.2-1.0 \mathrm{~cm}$ in length) were conducted at the Hokkaido Research Organization, Forest Research Development, Forest Products Research Institute (FPRI), Asahikawa, Hokkaido, and at the Dalton Co., Ltd. Tokyo Test Center, Itabashi, Tokyo.

\section{6 Refining of EFB fibers and EFB pellets}

The refining of EFB fibers $(0.5-4.0 \mathrm{~cm}$ in length) was kindly undertaken by Dr. Makoto Fukino of FPRI, Asahikawa, Hokkaido. Machine conditions such as the pressure of the steam boiler source $(2 \mathrm{MPa})$, temperature of the refiner $\left(148^{\circ} \mathrm{C}\right)$, and temperature of the dryer $\left(210^{\circ} \mathrm{C}\right)$ were defined in advance. To produce refined EFB fibers, the TMP refiner was set to a disk-refining pressure of 0.7 $\mathrm{MPa}, 166^{\circ} \mathrm{C}$ refining temperature and $0.15 \mathrm{~mm}$ disk clearance. These conditions were very important because the steam pressure induces change in the chemical components of the fibers, and it is well-known that the physical and mechanical properties of the refined fibers are strongly influenced by the refining pressure as a result ${ }^{15)}$. Refining of the EFB pellets at $0.4 \mathrm{MPa}\left(140^{\circ} \mathrm{C}\right)$ was kindly performed by Kumagai Riki Kogyo Co., LTD, Nerima, Tokyo using a disk clearance of $0.15 \mathrm{~mm}$.

\section{7 Decay testing}

Decay testing was conducted on blocks of fiberboard made from unrefined EFB fibers and on MDF produced from refined MLH fibers according to JIS Z 2101 and K 1571. The decay test results were considered acceptable if the weight loss of sugi (Cryptomeria japonica) wood specimens was greater than $30 \%$ for Fomitopsis palustris (brown -rot fungus), and greater than $15 \%$ for Trametes versicolor (white-rot fungus).

To provide a growth medium, sea sand in a glass jar was infused with nutrient solution and fungal inoculum of $F$. palustris or $T$. versicolor. When mycelium fully covered this medium, three replicate specimens of EFB fiberboard or control material prepared by sterilizing with gaseous ethylene oxide were placed on top of growing mycelium in the glass jar. A plastic mesh spacer was used between the specimens and mycelium for $F$. palustris. The test jars were then incubated at $27^{\circ} \mathrm{C}$ for 12 weeks, and the extent of fungal attack in this time was expressed as the average mass loss (\%) calculated from the oven-dried weights of specimens before and after the decay procedure. 


\section{Results and discussion}

\subsection{Properties of chemically pretreated mechanical pulp for paperboard}

\subsubsection{Effect of pretreatment on yield loss}

Wan Rosli et al ${ }^{18)}$ used sodium hydroxide $(\mathrm{NaOH})$ at room temperature as a chemical pretreatment to produce serviettes from EFB, though in this study $\mathrm{NaOH}$ at $121^{\circ} \mathrm{C}$ was used for chemical pretreatment of EFB. Rosnah et $a l .^{19)}$ also demonstrated that the time of alkaline treatment has a significant effect on the softening of EFB. With tropical bamboo, pretreatment by soaking in $2 \% \mathrm{NaOH}$ for $6 \mathrm{~h}$ is known to affect significantly the properties of the mechanical pulp ${ }^{20}$. However, using alkaline pretreatment to improve the strength of EFB materials may cause a decrease in yield. As shown in shown in Table 1, we observed that an increase in $\mathrm{NaOH}$ dosage caused yield loss, as did increasing the pretreatment period except when the final liquor $\mathrm{pH}$ (6.20) was sufficient to re-precipitate previously dissolved hemicellulose. Khakifirooz et al ${ }^{211}$ and Fatehi et al ${ }^{22)}$ have also observed a decrease in mechanical pulp yield with increasing alkali dosage. The results from EFB suggest that the yield loss should be caused by a reduction in hemicellulose and organic acid.

\subsubsection{Effect of pretreatment on fractionation of re- fined fibers}

There are two disks in the TMP refiner, one of which is bound to a moving rotor, while the other is a static stator. The space between these two disks is termed the refining zone, and is where materials are processed gradually from the feeder to the outlet. In this study, refining of pretreated EFB fibers was carried out under atmospheric condition, as it was found that fibrous materials like EFB could not be processed smoothly into the refining zone under pressurized conditions and so needed to be fed manually. As shown in Fig. 1, the biggest rate fraction of the five fiber fractions obtained by refining with a 0.15 or 0.20 $\mathrm{mm}$ disk clearance was the fraction obtained with an open-

Table 1 Effect of chemical pretreatment on yield loss

\begin{tabular}{cccc}
\hline NaOH dosage & Treatment time & \multicolumn{2}{c}{ After pretreatment at $121^{\circ} \mathrm{C}$} \\
\cline { 3 - 4 }$(\%)$ & $(\mathrm{h})$ & Liquor $\mathrm{pH}$ & Yield $(\%)$ \\
\hline 0 & 1 & 6.76 & 94.9 \\
0 & 2 & 6.46 & 93.6 \\
0 & 3 & 6.20 & 94.0 \\
1 & 1 & 6.77 & 93.0 \\
1 & 2 & 6.77 & 92.6 \\
1 & 3 & 6.74 & 92.2 \\
2 & 1 & 7.76 & 92.0 \\
2 & 2 & 6.96 & 91.2 \\
2 & 3 & 6.90 & 87.3 \\
\hline
\end{tabular}

${ }^{\text {a) }}$ Liquor to EFB fiber ratio : $7 \mathrm{~L} / \mathrm{kg}$

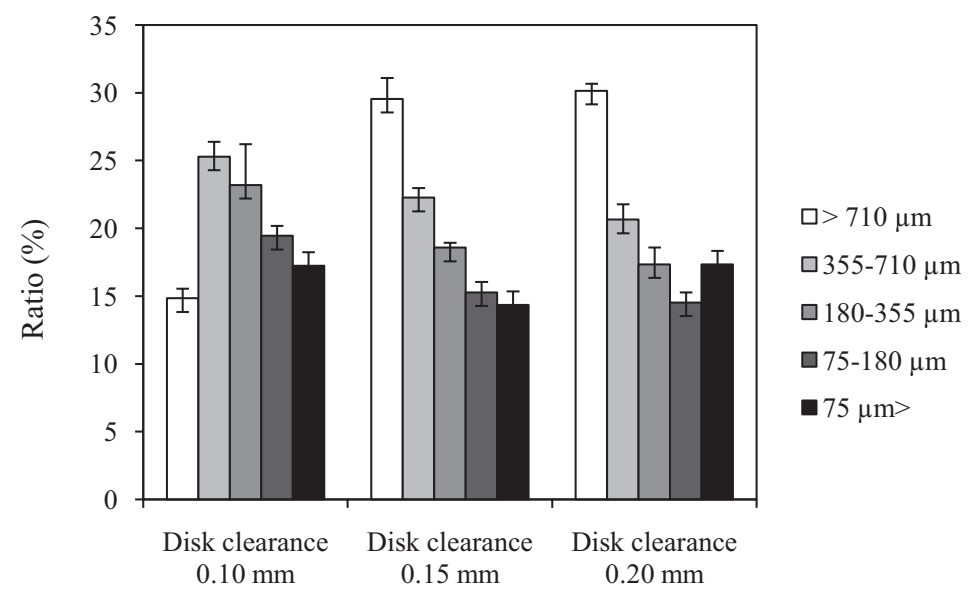

Fig. 1 Effect of refining disk clearance on fiber fractionation $(\mathrm{NaOH}$ dosage $: 0 \%$; pretreatment time $: 3 \mathrm{~h})$ 
ing size of more than $710 \mu \mathrm{m}$, while by a $0.10 \mathrm{~mm}$ disk clearance it was that with $355^{-710} \mu$ m opening size. This indicates that the fibrous EFB materials could not be sufficiently refined into single fibers (cells), and that instead shives of fibers remained in the pulp.

Fig. 2 shows that the ratio of small and fine fiber fractions with a $180-355 \mu \mathrm{m}$ opening, $75-180 \mu \mathrm{m}$ opening and $<75 \mu$ m opening decreased with increasing $\mathrm{NaOH}$ dosage. This can be explained by a decrease in fiber cutting through an increase in the flexibility of the fibers. Similarly, Fig. 3 shows that the ratio of small and fine fiber fractions with a $180-355 \mu \mathrm{m}$ opening and $75^{-180} \mu \mathrm{m}$ opening decreased with increasing pretreatment time from 1 to $2 \mathrm{~h}$, with the similarity in results between 2 and $3 \mathrm{~h}$ suggesting that $2 \mathrm{~h}$ of pretreatment is sufficient.

\subsubsection{Effect of pretreatment on physical properties of pulps}

It is well-known that refining can induce many changes in the properties of a fiber, such as its internal fibrillation, external fibrillation and cutting ${ }^{23)}$. One of the important consequences of refining is that it reduces fiber length, and hence has an adverse effect on the physical strength of paper. It is thought that internal fibrillation is caused by a compressive force from the disk absorbed to the material breaking the internal pore structure between cellulose microfibrils, which in turn makes the pore structure inside the cell wall expand and swell ${ }^{24}$ ).

Tensile strength is a function of fiber strength, fiber length and fiber-fiber bonding ${ }^{25}$, whereas tear strength is a measure of the perpendicular force required to separate multiple plies of paper through a specified distance and is therefore also influenced by the orientation of the fibers in a paper sheet ${ }^{26)}$. In Table 2, the tensile and tear indices of the pulp are shown alongside their respective pretreatment and refining conditions. It is evident from this that an increase in the $\mathrm{NaOH}$ dosage from 1 to $2 \%$ with a $2 \mathrm{~h}$ pretreatment time leads to an improvement in both the tensile and tear indices from $11.9 \mathrm{~N} \cdot \mathrm{m} / \mathrm{g}$ and $5.67 \mathrm{mN}$. $\mathrm{m}^{2} / \mathrm{g}$ to $19.7-20.4 \mathrm{~N} \cdot \mathrm{m} / \mathrm{g}$ and $6.67-8.75 \mathrm{mN} \cdot \mathrm{m}^{2} / \mathrm{g}$, respectively. These values are comparable with those of recycled pulp sheet from an old corrugated fiberboard box, which gave a tensile index of $19.8 \mathrm{~N} \cdot \mathrm{m} / \mathrm{g}$ and a tear index of $8.69 \mathrm{mN} \cdot \mathrm{m}^{2} / \mathrm{g}$. These indices were also improved by the extending the pretreatment period from 1 to $2 \mathrm{~h}$, but decreased when the time was extended further to $3 \mathrm{~h}$. The tensile strength increased with PFI beating from 7,500 to

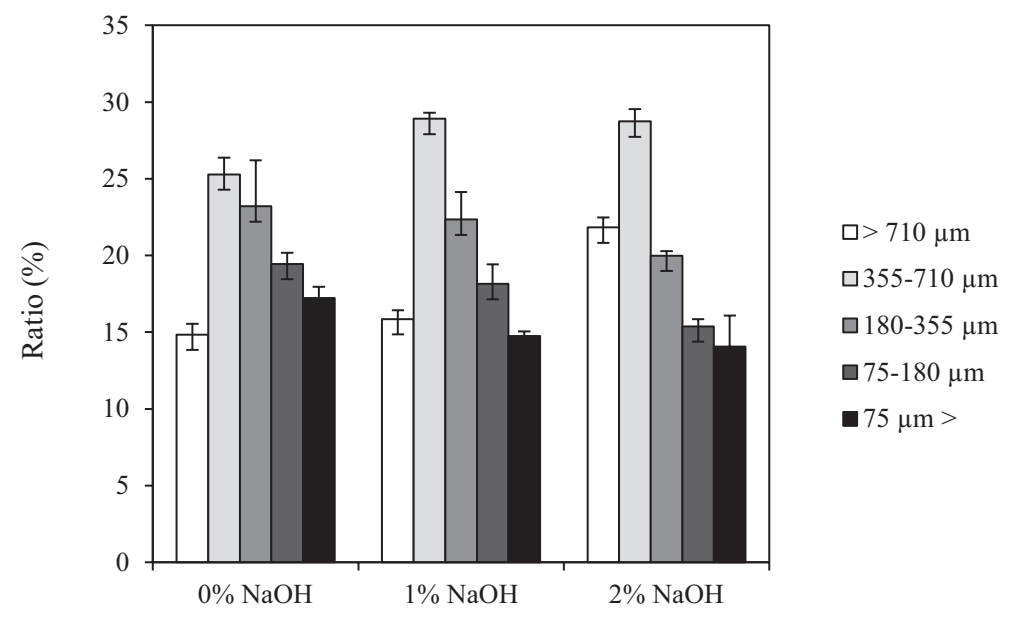

Fig. 2 Effect of $\mathrm{NaOH}$ dosage on fiber fractionation (Pretreatment time $: 3 \mathrm{~h}$; disk clearance $: 0.10 \mathrm{~mm}$ )

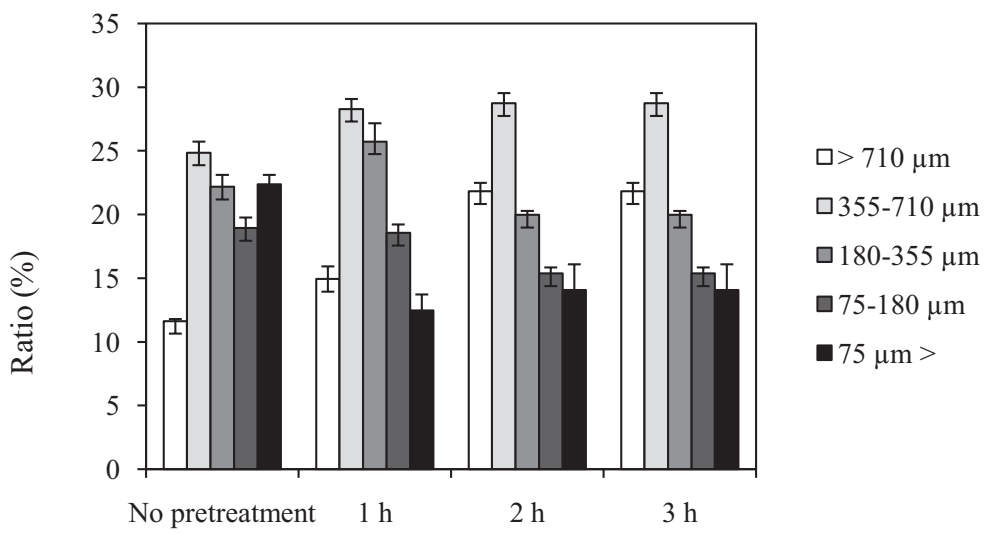

Fig. 3 Effect of pretreatment time on fiber fractionation ( $\mathrm{NaOH}$ dosage $: 2 \%$; disk clearance $: 0.10 \mathrm{~mm}$ ) 
Table 2 Effect of pretreatment and refining conditions on pulp physical properties

\begin{tabular}{cccccccc}
\hline \multicolumn{2}{c}{ Pretreatment } & \multicolumn{2}{c}{ Pefining } & \multicolumn{5}{c}{ Pulp physical properties } \\
\hline $\begin{array}{c}\mathrm{NaOH} \\
(\%)\end{array}$ & $\begin{array}{c}\text { Time } \\
(\mathrm{h})\end{array}$ & $\begin{array}{c}\text { TMP disk } \\
\text { clearance }\end{array}$ & $\begin{array}{c}\text { PFI } \\
\text { revolution }\end{array}$ & $\begin{array}{c}\text { CSF } \\
(\mathrm{ml})\end{array}$ & $\begin{array}{c}\text { Density } \\
\left(\mathrm{kg} / \mathrm{m}^{3}\right)\end{array}$ & $\begin{array}{c}\text { Tensile } \\
(\mathrm{N} \cdot \mathrm{m} / \mathrm{g})\end{array}$ & $\begin{array}{c}\text { Tear } \\
\left(\mathrm{mN} \cdot \mathrm{m}^{2} / \mathrm{g}\right)\end{array}$ \\
\hline 0 & 0 & 0.10 & 10,000 & 274 & 0.33 & 6.18 & 0.42 \\
0 & 2 & 0.10 & 10,000 & 278 & 0.33 & 7.96 & 4.88 \\
1 & 2 & 0.10 & 7,500 & 285 & 0.32 & 9.64 & 2.83 \\
1 & 2 & 0.10 & 10,000 & 242 & 0.33 & 11.9 & 5.67 \\
1 & 2 & 0.10 & 12,500 & 192 & 0.34 & 9.55 & 2.51 \\
2 & 2 & 0.10 & 7,500 & 250 & 0.35 & 19.7 & 8.75 \\
2 & 2 & 0.10 & 10,000 & 184 & 0.39 & 20.4 & 6.67 \\
2 & 2 & 0.10 & 12,500 & 154 & 0.39 & 18.6 & 4.01 \\
2 & 3 & 0.10 & 10,000 & 188 & 0.43 & 18.2 & 2.94 \\
\hline Recycled Pulp & - & - & 542 & 0.42 & 19.8 & 8.69 \\
\hline
\end{tabular}

${ }^{\text {a) }}$ Prepared from old corrugated fiberboard box

10,000 revolution, but decreased at 12,500 revolution. Based on this, EFB chemically pretreated mechanical pulp is considered suitable for use in the preparation of corrugating medium.

\subsection{Properties of fiberboard prepared from unre- fined EFB fibers}

\subsubsection{Mechanical properties}

The second step of this study was to determine the physical properties of fiberboard made using unrefined EFB fibers. As shown in Table 3, the MOR, MOE and IB of the fiberboard were $5.6 \mathrm{~N} / \mathrm{mm}^{2}, 648 \mathrm{~N} / \mathrm{mm}^{2}$, and $0.2 \mathrm{~N}$ / $\mathrm{mm}^{2}$, respectively, which are still below the minimum requirements mandated by the JIS A 5908 (particleboards). However, as these low values are largely due to the fibrous structure, they should improve when formed into a mat and combined with resin.

\subsubsection{Decay resistance}

Decay tests were conducted on blocks of fiberboard made from unrefined $\mathrm{EFB}$ fibers and MDF made from refined MLH fibers, with sugi (Cryptomeria japonica) board being used as a control specimen. In this test, the weight loss of the sugi control when exposed to $F$. palustris (brown -rot fungus) and T. Versicolor (white-rot fungus) was 31.6 and $27.4 \%$, respectively, which is considered an acceptable result according to JIS K 1571 (Fig.4). Meanwhile, Kartal and Green III ${ }^{27)}$ have discussed the results according to ASTM D 2017, wherein the decay resistance is divided into four categories based on the total weight loss after 16 weeks exposed to brown-rot fungus or $T$. Versicolor : 0-10\% : highly resistant ; 11-24\% : resistant ; $25-$ $44 \%$ : slightly resistant ; $>45 \%$ : non-resistant.

In this study, the weight loss of the sugi specimens was less than $50 \%$ after 12 weeks according to JIS K 1571, while the weight loss of the EFB fiberboard caused by $F$. palustris and T. versicolor was 9.9 and $18.0 \%$, respectively. The resistance of the EFB fiberboard to both brown-rot

Table 3 Mechanical properties of fiberboard made from unrefined EFB fibers and MDF made from refined MLH fibers

\begin{tabular}{lccccc}
\hline Material & $\begin{array}{c}\text { Density } \\
\left(\mathrm{kg} / \mathrm{m}^{3}\right)\end{array}$ & $\begin{array}{c}\left.\mathrm{MOR}^{\mathrm{a}}\right) \\
\left(\mathrm{N} / \mathrm{mm}^{2}\right)\end{array}$ & $\begin{array}{c}\mathrm{MOE}^{\mathrm{a})} \\
\left(\mathrm{N} / \mathrm{mm}^{2}\right)\end{array}$ & $\begin{array}{c}\left.\mathrm{IB}^{\mathrm{a}}\right) \\
\left(\mathrm{N} / \mathrm{mm}^{2}\right)\end{array}$ \\
\hline Fiberboard & $\mathrm{EFB}^{\mathrm{b})}$ & 671 & 5.6 & 648 & 0.2 \\
MDF & $\mathrm{MLH}^{\mathrm{c}}$ & 728 & 36.4 & 3,311 & 0.7 \\
\hline
\end{tabular}

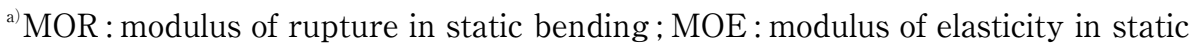
bending; IB : internal bond strength

${ }^{b)}$ Unrefined fibers

${ }^{c}$ Refined mixed light handwood fibers 


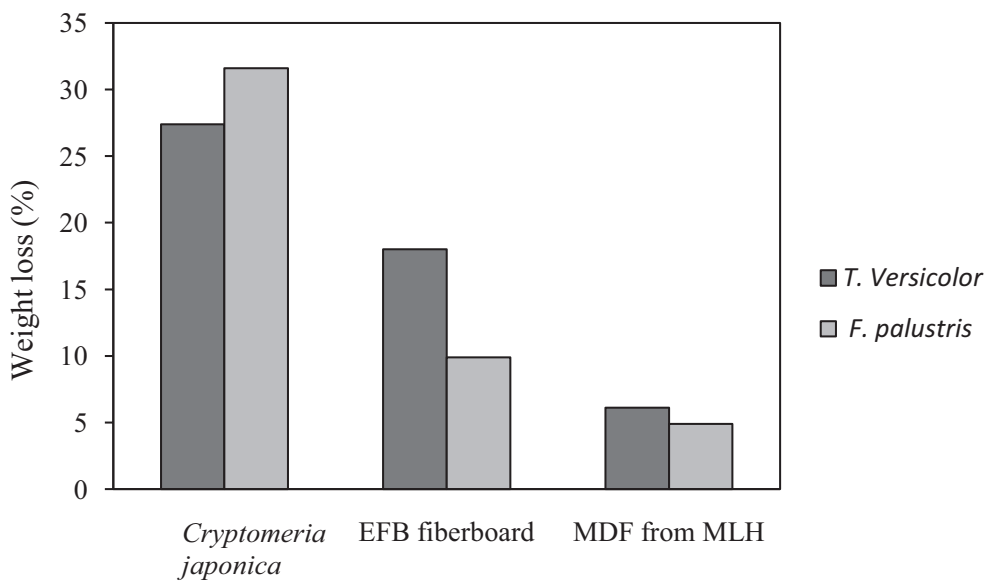

Fig. 4 Weight loss after decay testing

fungus and white-rot fungus was therefore better than that of sugi board.

\subsection{Properties of EFB fibers refined under pressur- ized conditions}

\subsubsection{Pelletizing of EFB fibers}

EFB materials cut to a size of $0.2-1.0 \mathrm{~cm}$ were pelletized at FPRI in Hokkaido prior to refining in order to facilitate feeding the fibers into the disk part of the refiner. Here, it was found that there were some necessary conditions for the raw materials to be formed into pellets: a moisture content of about $20 \%$, a fiber length of no more than $1.0 \mathrm{~cm}$. The diameter and length of the pellets formed were $0.5 \mathrm{~cm}$ and $1.5 \mathrm{~cm}$, respectively (Photo. 2).

\subsubsection{Refining of EFB fibers}

EFB pellets $(0.5 \mathrm{~cm}$ diameter and $1.5 \mathrm{~cm}$ length $)$ were refined to EFB fibers at $0.4 \mathrm{MPa}\left(140^{\circ} \mathrm{C}\right)$ using a TMP refiner, and then immediately air-dried without dewatering.
The refined fibers obtained were characterized according to JIS P 8207 and compared with a pretreated-mechanical pulp (Fig. 5). This found that TMP produces a smaller ratio of the fine fraction (less than $75 \mu \mathrm{m}$ ) than mechanical pulping, with a subsequent increase in the big size fraction

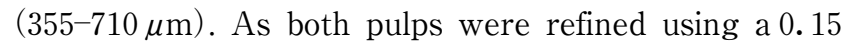
$\mathrm{mm}$ disk clearance, both should also contain shives of fibers given that the ratio of the biggest size fraction (more than $710 \mu \mathrm{m}$ ) was still high. However, a decrease in the amount of fine fraction and an increased amount of the big size can be caused by a decrease in fiber cutting due to an increased flexibility of the fibers when refined at a higher temperature of $140^{\circ} \mathrm{C}$.

Refined EFB fibers were also made from EFB materials at $0.7 \mathrm{MPa}\left(166^{\circ} \mathrm{C}\right)$ and were continuously dried by a hot -air dryer combined with the TMP refiner (Photo. 3). The results of fiber fractionation using screens in accordance

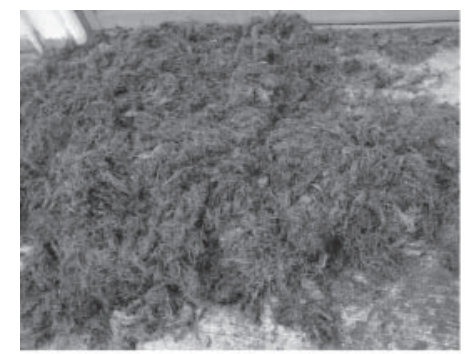

EFB Fiber (10-15 cm in length)

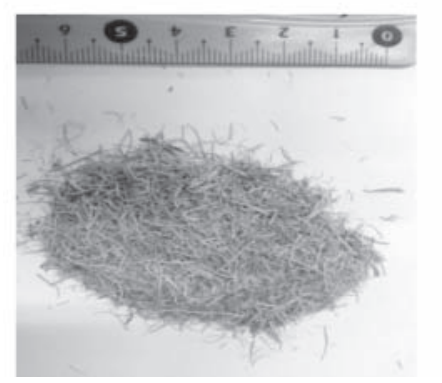

EFB Fiber (0.2-1.0 cm in length)

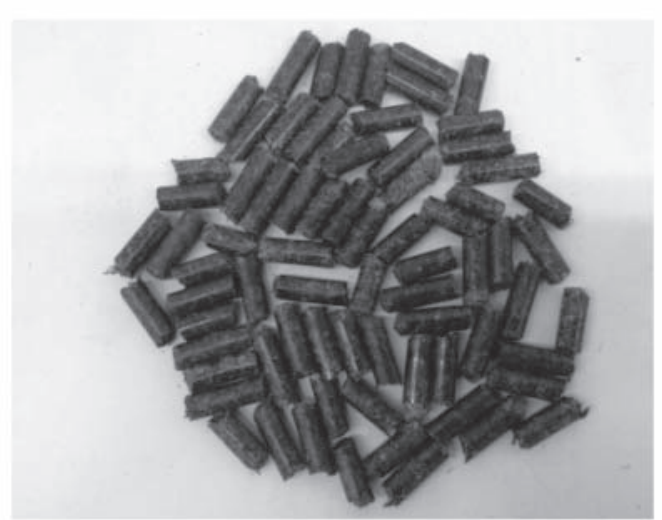

EFB Pellet (0.5 cm diameter and $1.5 \mathrm{~cm}$ length)

Photo. 2 Preparation of EFB fiber and EFB pellets for experimentation 


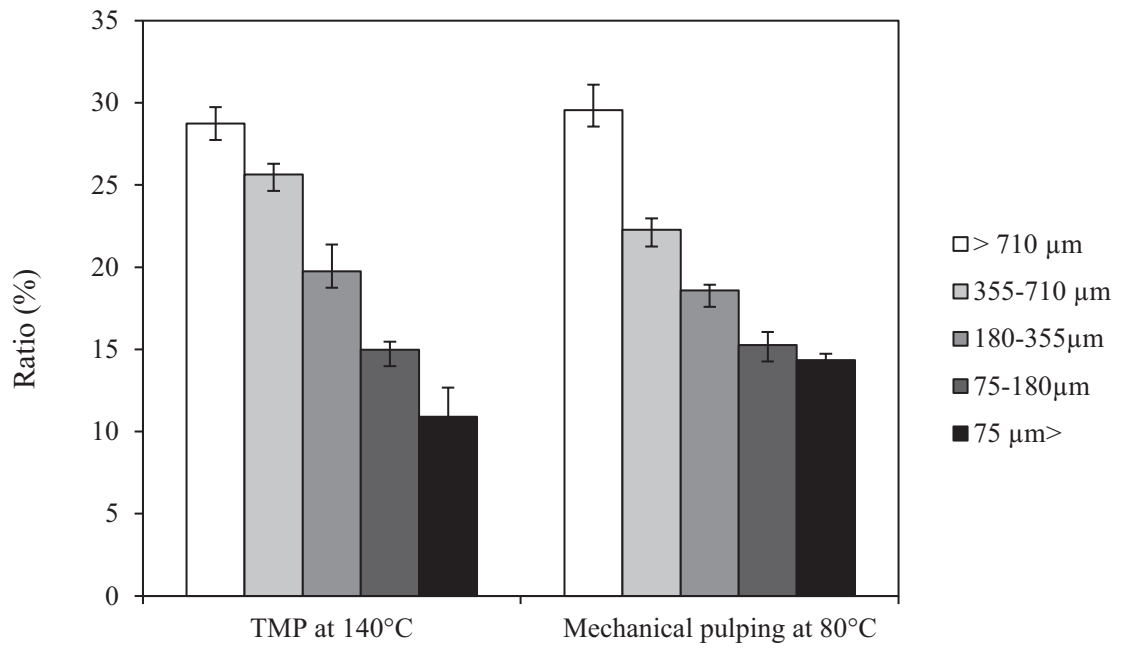

Fig. 5 Effect of refining temperature on fiber fractionation.(Disk clearance : $0.15 \mathrm{~mm}$; pretreatment of mechanical pulping : $121^{\circ} \mathrm{C}$ for $3 \mathrm{~h}$; mechanical pulping : atmospheric pressure)
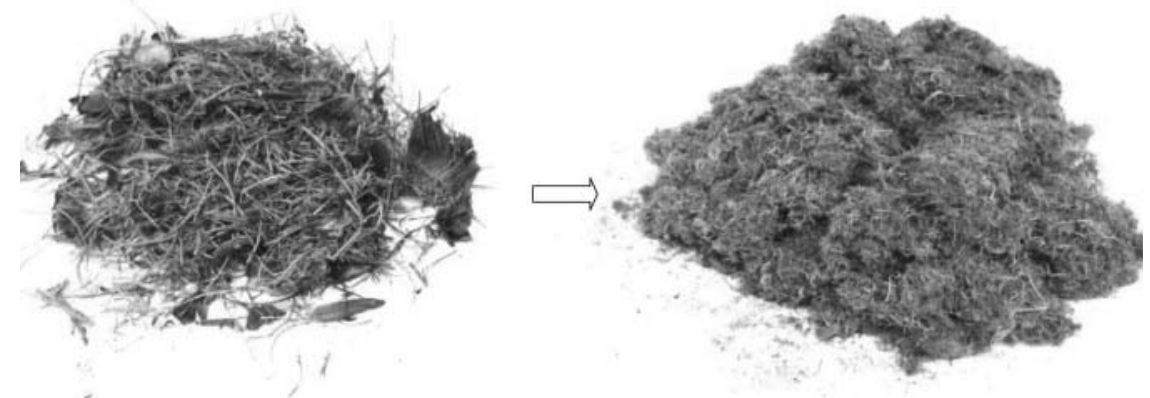

Photo. 3 Unrefined EFB fiber (left) and TMP-refined, hot air-dried pulp (right)

Table 4 Fiber length and width for refined EFB fibers

\begin{tabular}{|c|c|c|}
\hline & $\begin{array}{l}\text { Mean length } \\
(\mu \mathrm{m})\end{array}$ & $\begin{array}{c}\text { Mean width } \\
(\mu \mathrm{m})\end{array}$ \\
\hline \multicolumn{3}{|l|}{ Chemi-mechanical pulp ${ }^{\text {a) }}$} \\
\hline Before screen fractionation & 676 & 29.5 \\
\hline \multicolumn{3}{|l|}{ After screen fractionation } \\
\hline More than $710 \mu \mathrm{m}$ opening & $\mathrm{ND}^{\mathrm{b})}$ & ND \\
\hline 355-710 $\mu \mathrm{m}$ opening & 1,403 & 40.4 \\
\hline 180-355 $\mu \mathrm{m}$ opening & 750 & 29.9 \\
\hline 75-180 $\mu \mathrm{m}$ opening & 402 & 25.5 \\
\hline Pass of $75 \mu \mathrm{m}$ opening & 371 & 23.2 \\
\hline Thermo-mechanical at $166^{\circ} \mathrm{C}$ and hot air-dried pulp ${ }^{c}$ & 1,023 & 41.2 \\
\hline Thermo-mechanical at $140^{\circ} \mathrm{C}$ and warm air-dried pulp ${ }^{c)}$ & 737 & 42.1 \\
\hline EFB chemical pulp ${ }^{\mathrm{d})}$ & 556 & 18.0 \\
\hline
\end{tabular}

${ }^{\text {a) }} \mathrm{NaOH}$ dosage $: 2 \%$; pretreatment time $: 3 \mathrm{~h}$; disk clearance of refining $: 0.10 \mathrm{~mm}$

${ }^{\text {b) Not determined }}$

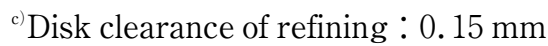

${ }^{\mathrm{d}}$ Reference 8) ; kappa number : 9.6 ; pulp yield : $31.1 \%$ 
with JIS P 8207 revealed the fiber length distribution characteristics of each pulp, but did not provide information as to the fiber length and fiber width of each pulp. These were therefore determined using a Lorentzen-Wettre fiber tester for a chemi-mechanical pulp and two kinds of thermo-mechanical pulps $\left(166\right.$ and $\left.140^{\circ} \mathrm{C}\right)$. As shown in Table 4, the chemi-mechanical pulp contained fibers that were longer and wider than those in the chemical pulp (prehydrolysis soda-AQ pulp prepared as a dissolving pulp). Furthermore, a comparison of the two kinds of thermo-mechanical pulps shows that longer and wider fibers are obtained by increasing the refining temperature from 144 to $160^{\circ} \mathrm{C}$. The fiber length and width of the dissolving pulp are considered to be small because of the low pulp yield, while the increase in temperature of TMP refining should increase fiber length by preventing the cutting of fibers.

\section{Conclusions}

The pulp properties indicate that the optimum conditions for chemical pretreatment and mechanical pulping under atmospheric pressure are $121^{\circ} \mathrm{C}$ for $2 \mathrm{~h}$ with $2 \%$ $\mathrm{NaOH}$, and a TMP refiner disk clearance of $0.10 \mathrm{~mm}$. The tensile and tear indices obtained under these conditions were $19.7-20.4 \mathrm{~N} \cdot \mathrm{m} / \mathrm{g}$ and $6.67-8.75 \mathrm{mN} \cdot \mathrm{m}^{2} / \mathrm{g}$, respectively, which are similar to the values for a pulp prepared from an old corrugated fiberboard box and indicate that EFB fibers can feasibly be used in the preparation of corrugating medium. The mechanical properties of fiberboard made from unrefined EFB fibers were still under those required by the JIS A 5908, but its resistance to attack by a brown-rot fungus (Fomitopsis palustris) and white -rot fungus (Trametes versicolor) was better than that of sugi (Cryptomeria japonica) specimens.

\section{Acknowledgements}

The authors are grateful for the assistance given by Mr. Agusta Samodra Putra and Mr. Roni Maryana, in testing the paper properties, and Ms. Nadia Nuraniya Kamaluddin, for the decay test. They would also like to express their gratitude to Dr. Ryota Kose, Assistant Professor at the Institute of Agriculture (Research Organization), Tokyo University of Agriculture and Technology, for the permission and guidance to use a JIS fiber classification screen. Particular gratitude is also extended to Dr. Hideaki Takahashi (Hokushin Co., Ltd.) and Dr. Makoto Fukino (Hokkaido Research Organization) for their valuable advice and assistance.

\section{References}

1) Reddy N, Yang Y (2005) Biofibers from agricultural by-products for industrial applications. Trends Biotechnol 23 : 22-27

2) Judt M (1993) Non-wood plant fibers, will there be a come-back in paper-making? Ind Crops Prod $2: 51-$ 57

3) Tanaka R, Wan Rosli DW, Magara K, Ikeda T, Hosoya S (2004) Chlorine-free bleaching of kraft pulp from oil palm empty fruit bunches. Jpn Agric Res Q 39 : 275279

4) Jimenez L, Serrano L, Rodriguez A, Sanchez R (2009) Soda-anthraquinone pulping of palm oil empty fruit bunches and beating of the resulting pulp. Bioresour Technol $100: 1262-1267$

5) Singh P, Sulaiman O, Hashim R, Leh CP, Singh RP (2013) Using biomass residues from oil palm industry as a raw material for pulp and paper industry : Potential benefits and threat to the environment. Environ Dev Sustain 15:367-383

6) Wan Rosli DW, Leh CP, Zainuddin Z, Tanaka R (2003). Optimisation of soda pulping variables for preparation of dissolving pulp from oil palm fibre. Holzforschung $57: 106-114$

7) Leh CP, Wan Rosli WD, Zainuddin Z, Tanaka R (2008) Optimisation of oxygen delignification in production of totally chlorine-free cellulose pulps from oil palm empty fruit bunch fibre. Ind Crops Prod 28 : 260-267

8) Harsono, Putra AS, Maryana R, Rizaluddin AT, H'ng YY, Nakagawa-izumi A, Ohi H (2015) Preparation of dissolving pulp from oil palm empty fruit bunch by prehydrolysis soda-anthraquinone cooking method. J Wood Sci [to be submitted]

9) Khalil HPS, Alwani MS, Omar AKM (2006) Chemical composition, anatomy, lignin distribution, and cell wall structure of Malaysian plant waste fibers. Bioresources 1:220-232

10) Shahriarinour M, Wahab MNA, Mustafa S, Mohamad R, Ariff AB (2011) Effect of various pretreatments of oil palm empty fruit bunch fibres for subsequent use as substrate on the performance of cellulose production by Aspergillus terreus. Bioresources 6 : 291-307

11) Koba Y, Ishizaki A (1990) Chemical composition of palm fibres and its feasibility as cellulosic raw material for sugar production. J Agric Biol Chem 54 : 1183 $-1187$

12) Zaidon A, Nizam AMN, Faizah A, Paridah MT, Jalaludin H, Nor MYM, Yuziah MYN (2007) Efficacy of pyrethroid and boron preservatives in protecting particleboards against fungus and termite. J Trop For Sci 20 : 57-65

13) Rozman HD, Tay GS, Kumar RN, Abusamah A, Ismail H (2001). Polypropylene-oil palm empty fruit bunchglass fibre hybrid composites: A preliminary study on the flexural and tensile properties. Eur Polym J 37 : 1283-129

14) Husain Z, Zainac Z, Z. Abdullah $Z$ (2002) Briquetting 
of palm fibre and shell from the processing of palm nuts to palm oil. Biomass Bioenergy 22 : 505-509

15) Xing C, Wang S, Pharr GM, Groom LH (2008) Effect of thermo-mechanical refining pressure on the properties of wood fibers as measured by nanoindentation and atomic force microscopy. Holzforschung $62: 230-$ 236

16) Li B. Li H, Zha Q, Bandekar R, Alsaggaf A, Ni Y (2011) Review : Effects of wood quality and refining process on TMP pulp and paper quality. Bioresources 6 : 3569-3584

17) Xu EC, Sabourin MJ, Cort JB (1999) Evaluation of APMP and BCTMP processes for market pulp properties from South American eucalyptus species. Tappi J 82 (12) : 75-82

18) Wan Rosli WD, Wahid KA, Law KN (2013) Cold soda pulping of oil palm empty fruit bunch (OPEFB) . Bioresources 8 : 6151-6160

19) Rosnah MY, Ghzali A, Wan Rosli WD, Dermawan YM (2010) Influence of alkaline peroxide treatment duration on the pulpability of oil palm empty fruit bunch. World Appl Sci J 8 (2) : 185-192

20) Ashaari $Z$, Salim S, Halis R, Nor M, Yusof M, Sahri MH (2010) Characteristics of pulp produced from refiner mechanical pulping of tropical bamboo (Gigantochloa scortechinii). Pertanika J Trop Agric Sci 33 (2) : 251258

21) Khakifirooz A, Ravanbakhsh F, Samariha A, Kiaei M (2013) Investigation the possibility of Chemi-mechanical pulping of bagasse. Bioresources $8: 21-30$

22) Fatehi P, Hosseinpour R, Latibari AJ (2011) Chemimechanical pulping of canola straw for the production of corrugating medium paper grades. Appita J 64 (5) : 450-455

23) Karnis A (1994) The mechanism of fibre development in mechanical pulping. J Pulp Paper Sci 20 : 280-288

24) Maloney $T$, Paulapuro $H$ (1999) The formation of pores in the cell wall. J Pulp Paper Sci 25 : 430-436

25) Tappi Test Methods 2002-2003 : (2002) “Tappi Test Method T 494 : Tensile properties of paper and paperboard (using constant rate of elongation apparatus)", Tappi Press

26) Tappi Test Methods 2002-2003 : (2002)" Tappi Test Method T 414 : Internal tearing resistance of paper (Elmendorf-type method)", Tappi Press

27) Kartal SN, Green III F (2003) Decay and termite resistance of medium density fiberboard (MDF) made from different wood species. Int Biodeteri Biodegr $51: 29-$ 35 